\title{
Incidence of Infant Respiratory Disease can be Decreased by Vitamin A Supplement: A system review and meta analyses
}

\author{
Yuanyuan $\mathrm{Li}^{1}$, Ruoyu Zhang ${ }^{2}$, Mimgqing Zhong ${ }^{1}$, Jiaxuan $\mathrm{Li}^{1}$, Haoyu Yin ${ }^{1}$, Zhiyuan Ma1, \\ Chengyuan Zhang ${ }^{1}$, and Qingfeng Zhai ${ }^{1}$
}

${ }^{1}$ Weifang Medical University

${ }^{2}$ Weifang Medical College

May 18, 2020

\begin{abstract}
Objective: To investigate whether vitamin A are associated with a lower fracture incidence in infants' respiratory system diseases. Method: A systematic literature search of articles update to April 2020 was conducted via PubMed, Web of Science, and the Chinese National Knowledge Infrastructure (CNKI), Chinese biomedical literature database (CBM), and the references of the retrieved articles. Fixed- or random-effect models were used to summarize the estimates of OR with 95\% CIs for the vitamin A are associated with a lower fracture incidence in infants' respiratory system diseases. Result: This study includes 18 articles. Compared with control group, the experimental group's infant babies are less likely to get poor health outcomes. Especially ,suffering from respiratory related disease, such as,neonatal respiratory distress syndrome (NRDS) (OR $=0.79)$, neonatal pneumonia $(\mathrm{OR}=0.51)$, neonatal ALRI to acute lower respiratory infection $(\mathrm{OR}=0.66)$, neonatal bronchial pulmonary hypoplasia bronchopulmonary dysplasia of premature infants $(\mathrm{BPD})(\mathrm{OR}=0.49)$. All test of the difference had ensured statistical significance $(\mathrm{P}<0.05)$. Conclusion: This meta-analysis indicated that Vitamin A intake was associated with a decreased risk of infants' respiratory system related diseases. Further researches should be conducted to confirm the findings in our study and better clarify the potential biological mechanisms.
\end{abstract}

\section{Hosted file}

mian document.doc available at https://authorea.com/users/323561/articles/452159-incidenceof-infant-respiratory-disease-can-be-decreased-by-vitamin-a-supplement-a-system-reviewand-meta-analyses

\section{Hosted file}

table.doc available at https://authorea.com/users/323561/articles/452159-incidence-ofinfant-respiratory-disease-can-be-decreased-by-vitamin-a-supplement-a-system-review-andmeta-analyses 

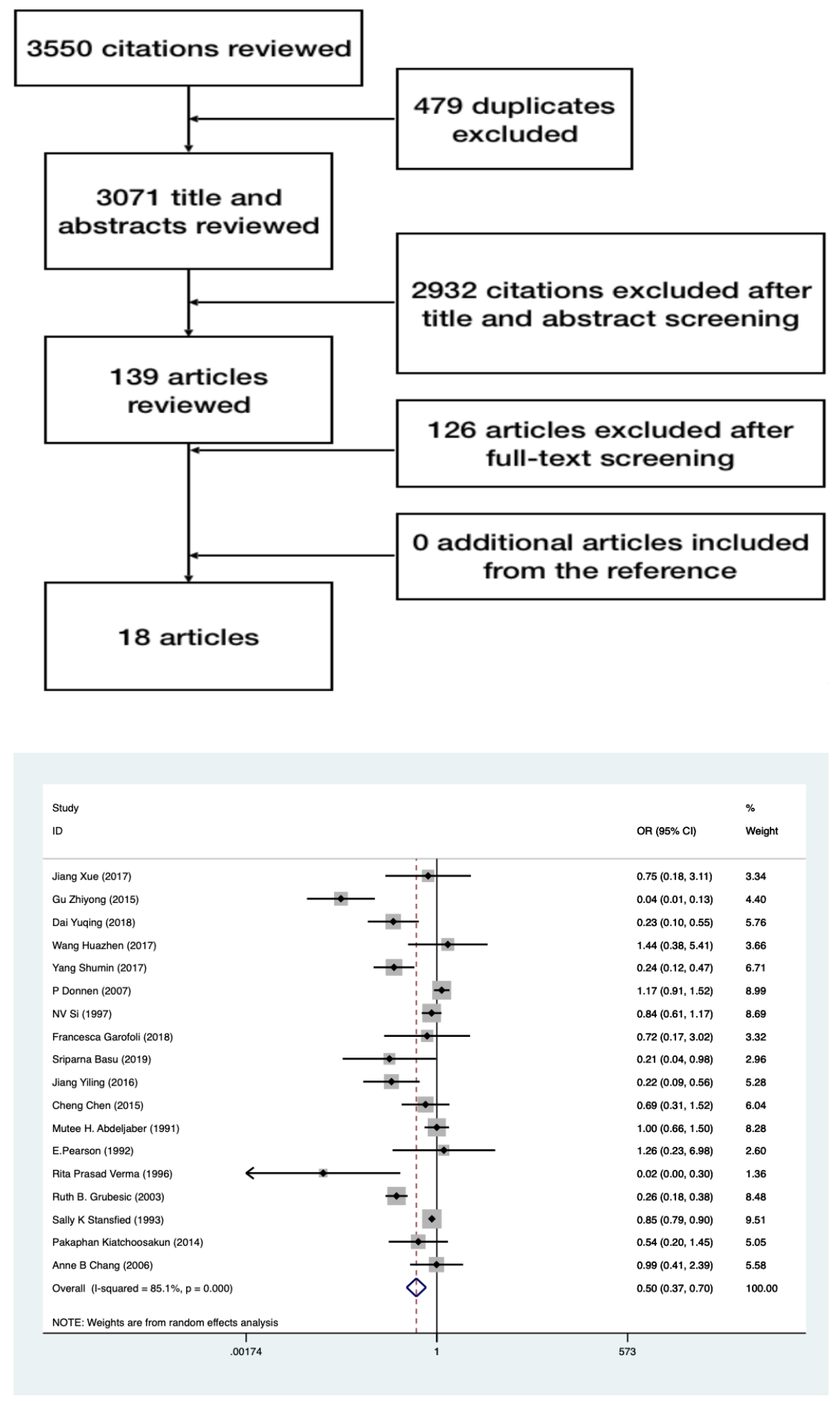


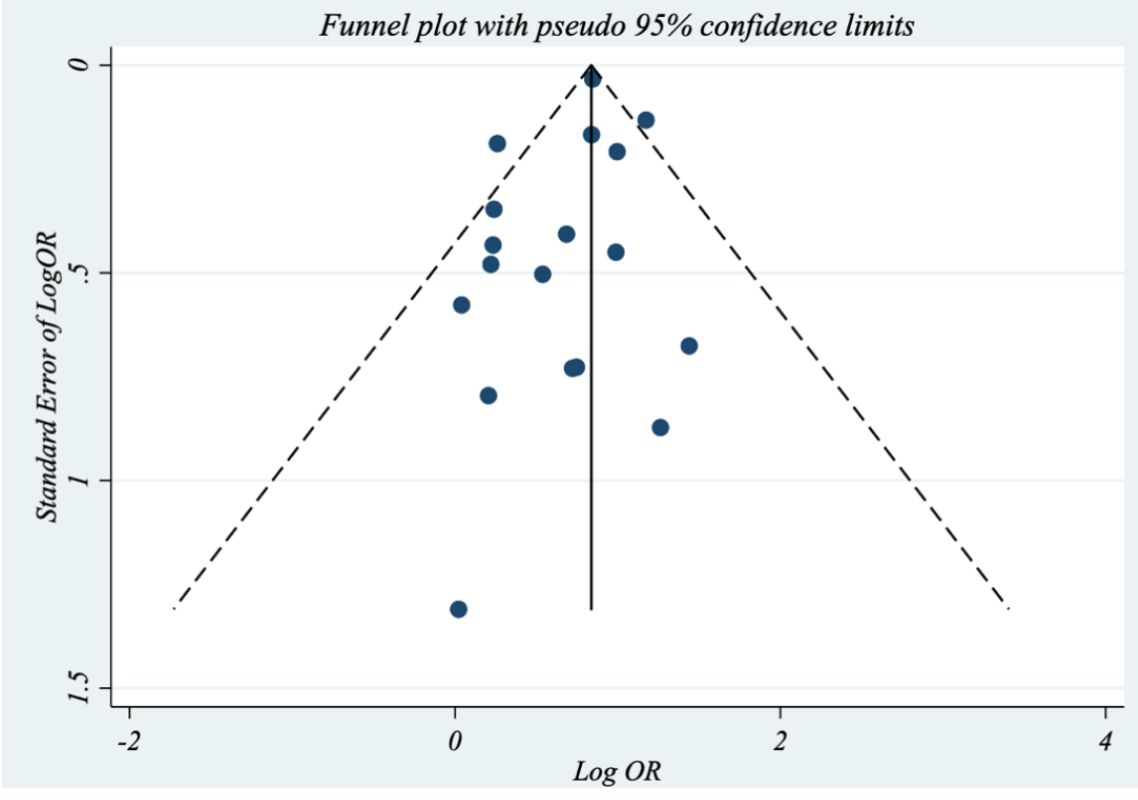

